\title{
Experimental study of beams on yielding supports with thrust
}

\author{
Oleg Kumpyak ${ }^{1}$, Zaur Galyautdinov ${ }^{1, *}$, and Daud Galyautdinov ${ }^{1}$ \\ ${ }^{1}$ Tomsk State University of Architecture and Building, 634003 Tomsk, Russia
}

\begin{abstract}
The design of reinforced concrete structures which are subjected to static and intensive dynamic loading requires taking into account the occurrence of thrust reaction resulting in significant increase in strength and crack resistance. Application of yielding supports for the purpose of increasing the energy capacity of structures shall also be considered. The present research aims to define feasibility of yielding supports application in thrust structures. The paper presents the outcomes of experimental studies of reinforced concrete beam structures on yielding supports subjected to thrust under static and short-term dynamic loading. The influence of thrust on the strength, deformation property and crack resistance of reinforced concrete structures under static and short-term dynamic loading was investigated. The combined use of yielding supports and the restriction of horizontal displacement of the support contour were also considered in the study. Research results testify on the positive outcome when yielding supports are applied in the structures subjected to thrust.
\end{abstract}

\section{Introduction}

The basic methods of reinforced concrete (RC) structures analysis under short-term dynamic loading are based on prerequisites which do not always consider the peculiar features of real structure operation to the full extent. All real structures have connections in their bearing member (anchoring of elements on the supports, grouting the gaps between the elements faces), which prevent the horizontal displacement of support sections during loading and result in thrust occurrence. A number of theoretical and experimental studies reflect a significant positive influence of thrust reaction on the stress-strain state of the beams [1-5].

The mentioned influence under static loading is studied rather well [1, 3, 5]. Analysis of the numerical analysis of the structures under static loading subjected to thrust indicate the increase of their load-bearing capacity depending on the reinforcement percentage of the cross-section $(\mu)$ and flexibility of the supporting contour (c) [3] (Fig. 1).

The influence of thrust on the structural resistance under dynamic loading is controversial: on the one hand, the presence of the horizontal reaction increases the loadbearing capacity of the element; on the other hand, it reduces its deformation property thus

\footnotetext{
* Corresponding author: GazR@yandex.ru
} 
leading to reduction of plastic deformation stage. This issue was considered in the works of N.N. Popov and B.S. Rastorguev [6], T.N. Vinogradova [3], and I.N. Tikhonova [5]. The thrust occurrence is necessary to consider as when structures are subjected to the action of emergency loads in a number of cases the work of reinforcement is acceptable beyond the elasticity range. Therefore, it causes increase in the strain of tensile area and the growth of the horizontal reaction accordingly.

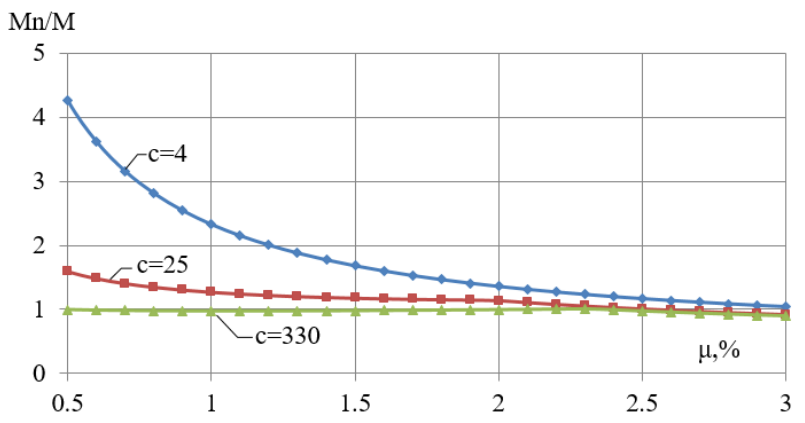

Fig. 1. Alteration of the load-bearing capacity of the beams subjected to thrust under static loading depending on the reinforcement percentage $(\mu)$ by various supports ductility (c): Mn - ultimate bending moment taking into account thrust; $\mathrm{M}$ - ultimate bending moment without considering thrust.

The dependence of deformation property on the load-bearing capacity under action of the time-constant load on the beam is illustrated in Figure 2.

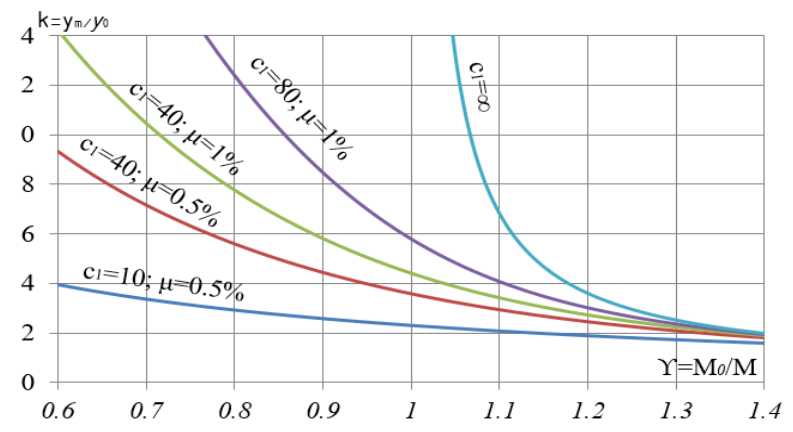

Fig. 2. The dependence of $k$ on $\Upsilon$ for the beams under the action of suddenly-applied time-constant load $\mathrm{P}_{0}=$ const [2]: $\mathrm{M}_{0}-$ the bending moment at the end of elastic stage; $\mathrm{MP}-$ the bending moment of the acting load; $\mathrm{y}_{\mathrm{m}}$ - the ultimate deflection of structure; $\mathrm{y}_{0}$ - the elastic deflection of structure; $\mathrm{c}-$ flexibility of the supporting contour.

As can be seen from Figure 2, thrust has significant effect on the deformation property of the structure. Decrease in the flexibility of the horizontal supports $(c)$ and the percentage of longitudinal reinforcement $(\mu)$ leads to reduction of the beam strain.

Use of yielding supports contributes to the increase in structural resistance towards dynamic loading. Experimental results of the beams on yielding supports $[7,8]$ demonstrate great effectiveness of their application under high intensity dynamic loadings. Moreover, the better effect was observed during supports straining in elasto-plastic stage.

Thus, application of yielding supports and consideration of horizontal displacements restriction is a rather relevant issue which requires in-depth study. 


\section{Experimental}

For the assessment of the stress-stain state of RC beam structures on yielding supports subjected to thrust under static and short-term dynamic loading the program of experimental studies was developed and implemented (Table 1). Six beams were designed and manufactured, their size being $1900 \times 150 \times 220 \mathrm{~mm}$. Heavy concrete of grade B35 was used for the beams production. The beams were reinforced with the spatial frame. Coldworked reinforcement $\varnothing 5 \mathrm{~mm}$ grade Bp500 with the span $50 \mathrm{~mm}$ in near-support area and $130 \mathrm{~mm}$ in the mid-span was used as a lateral reinforcement; while hot-rolled reinforcement $\varnothing 6 \mathrm{~mm}$ grade A240 in the compressed area and $\varnothing 10 \mathrm{~mm}$ grade A500 in tensile area was used as a longitudinal reinforcement. For the reinforcement of front areas of the beams mesh with the cell size of $50 \times 50 \mathrm{~mm}$ was made from cold-worked reinforcement $\varnothing 5 \mathrm{~mm}$ grade Bp500, 7 meshes were installed on each side, and the angle-irons $100 \times 10 \mathrm{~mm}$ were placed (Fig. 3).

Table 1. Experimental program.

\begin{tabular}{|c|c|c|c|c|c|}
\hline Loading type & \multicolumn{2}{|c|}{ Static load } & \multicolumn{2}{c|}{ Dynamic load } \\
\hline Support type & \multicolumn{2}{|c|}{ Rigid supports } & \multicolumn{2}{c|}{ Rigid supports } & $\begin{array}{c}\text { Yielding supports } \\
\text { (elasto-plastic stage) }\end{array}$ \\
\hline Percentage of reinforcement & \multicolumn{2}{|c|}{$\mu=0.5 \%$} & \multicolumn{2}{|c|}{$\mu=0.5 \%$} & $\mu=0.5 \%$ \\
\hline $\begin{array}{c}\text { The flexibility value of the } \\
\text { horizontal contour c }\end{array}$ & $\infty$ & 25 & $\infty$ & 25 & 25 \\
\hline Sample code & BS-1 & $\begin{array}{c}\text { BS-2T, } \\
\text { BS-3T }\end{array}$ & BD-4 & BDT-5 & BDTY-6 \\
\hline Number of samples & 1 & 2 & 1 & 1 & 1 \\
\hline
\end{tabular}

Notes:

$\mathrm{c}_{1}=\infty-$ corresponds to the lack of the thrust contour;

$\mathrm{c}_{1}=25$ - corresponds to the presence of the thrust contour presented by two tension bars, $70 \mathrm{~mm}$ in diameter;

Notation: "B" - RC beam; "S" - static loading; "D" - short-term dynamic loading (falling weight $450 \mathrm{~kg}$, from the height of $750 \mathrm{~mm}$ ); "T" - presence of the thrust structure; "Y" - yielding support (made from hollow-section tubes: the outer diameter $32 \mathrm{~mm}$, the inner diameter $26 \mathrm{~mm}, 1=50 \mathrm{~mm}$ ); "1...6" - the structure No.

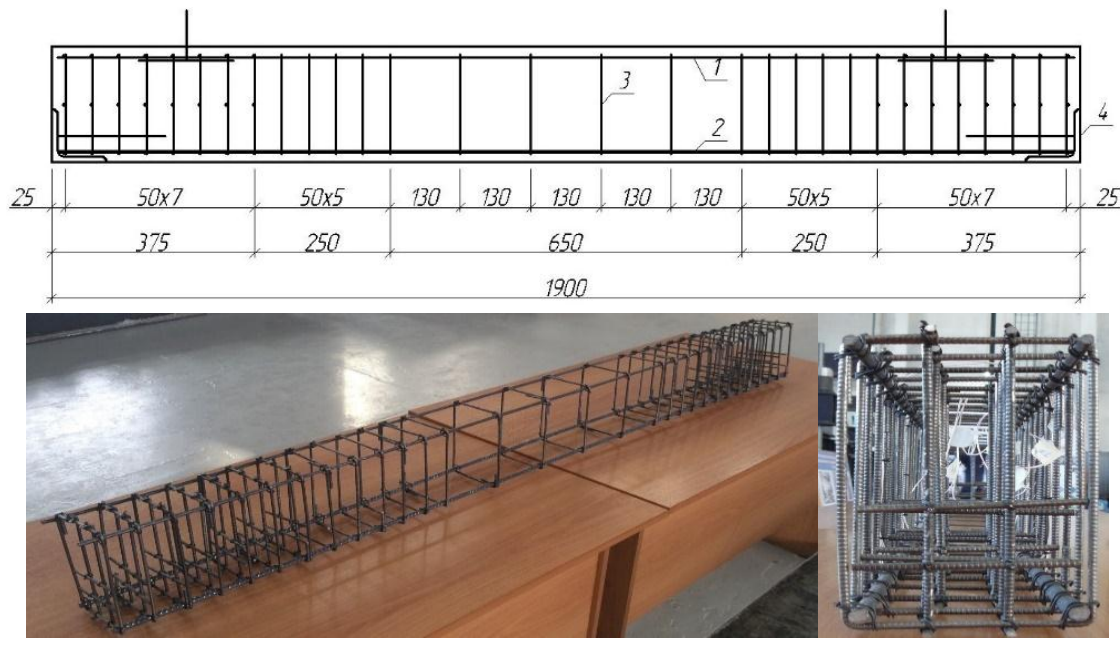

Fig. 3. The scheme of reinforcement of concrete structures under study: 1 - reinforcement $\varnothing 6 \mathrm{~mm}$ grade A240; 2 - reinforcement $\varnothing 10 \mathrm{~mm}$ grade A500; 3 - reinforcement $\varnothing 5 \mathrm{~mm}$ grade Bp500; 4 equal leg angle $100 \times 10 \mathrm{~mm}$. 
The whole complex of measuring facilities was placed on the tested samples. Inductive displacement sensor Waycon RL150 was used for displacement measurement. Acceleration gauges DHE 100023 were applied for acceleration measurement. Force measuring strain gauge DST 4126 was used for measuring the system response and the value of the support response was defined by means of dynamometric supports (Russian Federation utility model patent No. 161908). Visualization of the crack development pattern during shortterm dynamic loading was conducted using high-speed camera with the speed 2500 shots/sec (Photron Fastcam SA-2). The facilities were connected to the computer program Mic-036R and Mic-400D.

Testing facility was developed and produced (Fig. 4) for implementation of the experimental program, the corresponding patents were obtained for that purpose (Russian Federation utility model patent No.147262, No.148401).

a)

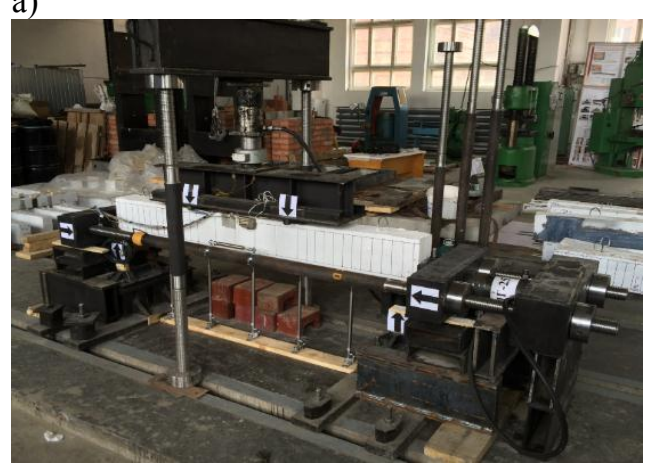

b)

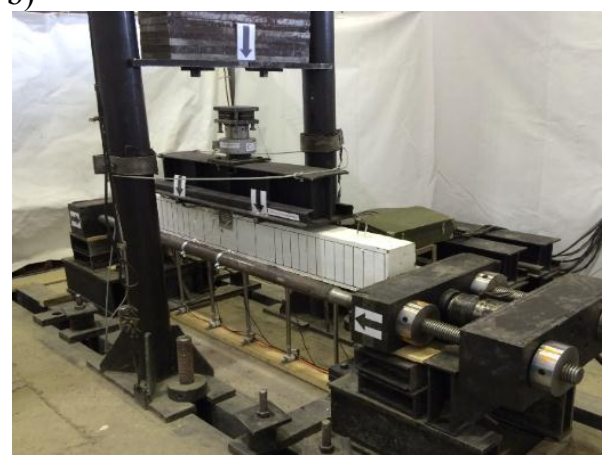

Fig. 4. Test facility for RC beams: under static loading subjected to thrust (a); under dynamic loading with thrust on yielding supports (b).

The RC beam under study was placed on dynamometric supports which provide hinge supporting. The supports were fixed on the strong floor, then the initial longitudinal force (thrust) was applied by the hydraulic jack through the traverse system connected by guide ways.

During static loading (Fig. $4 a$ ) the load was applied by means of hydraulic jack through distributive traverse in one thirds of the span, short-term dynamic loading was applied by means of falling weight of $450 \mathrm{~kg}$, from the height of $750 \mathrm{~mm}$ (Fig. $4 b$ ).

\section{Results}

Resulting from static testing for hinged beam not subjected to thrust the ultimate breaking load was $64 \mathrm{kN}$, and for the beam subjected to thrust it was $168 \mathrm{kN}$, the increase of loadbearing capacity by the load reached $262.5 \%$, while maximum deflections decreased by $235 \%$ (Fig. 5). Occurrence of the first cracks in the beam without thrust was observed at the load of $24 \mathrm{kN}$, and with thrust - at the load of $36 \mathrm{kN}$. According to the destruction patterns of the structure and crack formation it can be seen that the presence of thrust leads to increase in crack resistance of beams, and destruction occurs in concrete of the compressed area (Fig. 6). 


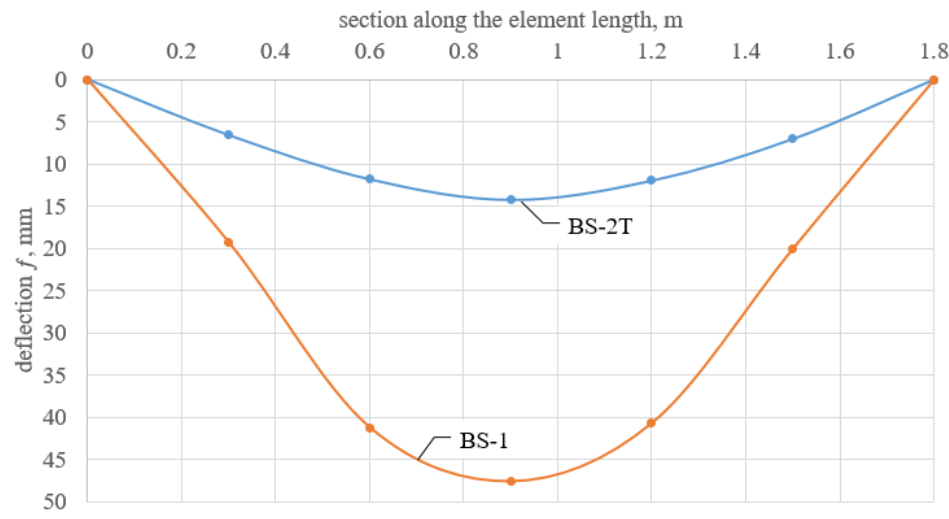

Fig. 5. The ultimate displacements of the beams BS-1, BS-2T under static loading.

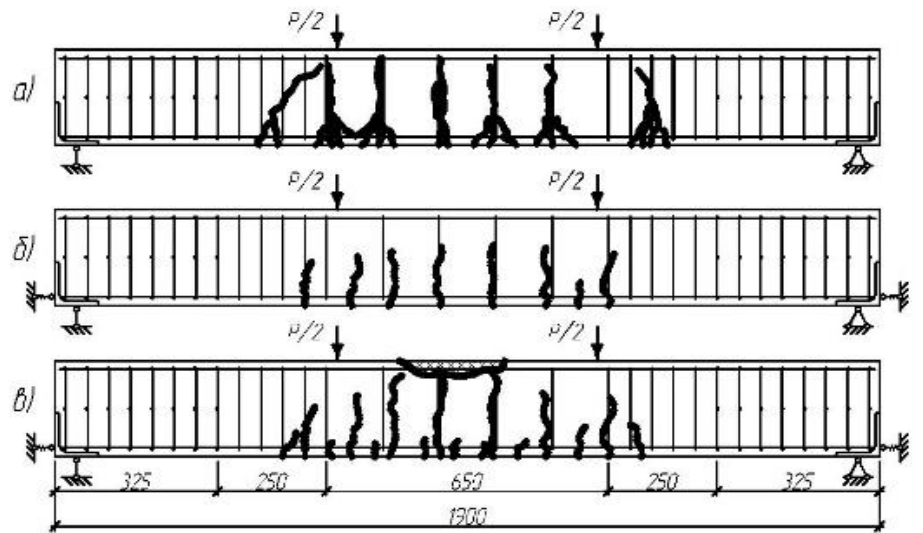

Fig. 6. The schemes of crack formation in the structures under static loading: a) BS-1, by $T=64 \mathrm{kN}$; b) BS-2T, by $\mathrm{T}=64 \mathrm{kN}$; c) BS-2T, by $\mathrm{T}=168 \mathrm{kN}$.

The results of dynamic testing of the reference samples with equal loading parameters show that application of yielding supports and the restrictive contour (BDTY-6) causes significant increase in crack resistance (Fig. 8).

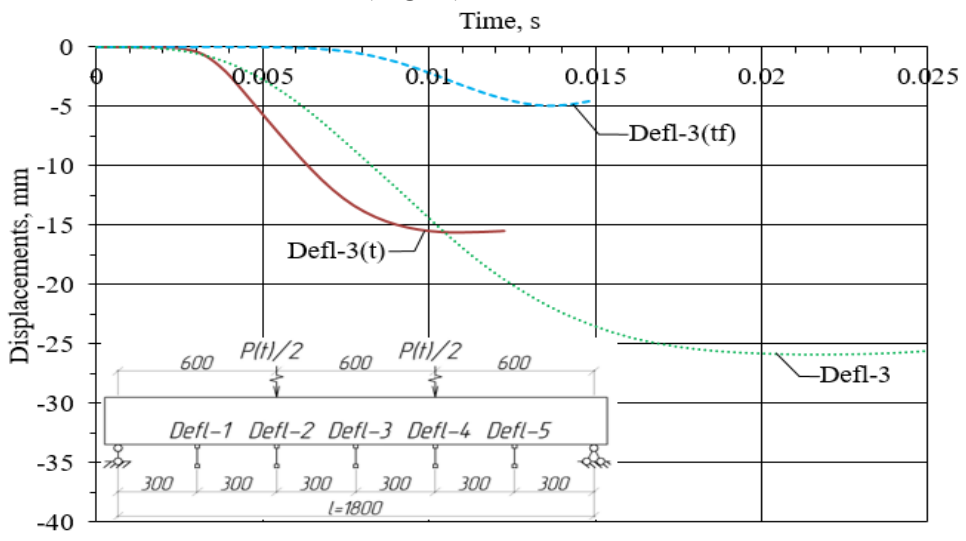

Fig. 7. Alteration in displacements of structures in the mid-span depending on the time: Defl-3 deflection of RC beam BD-4; Defl -3(t) - deflection of RC beam BDT-5; Defl -3(tf) - deflection of RC beam BDTY-6. 


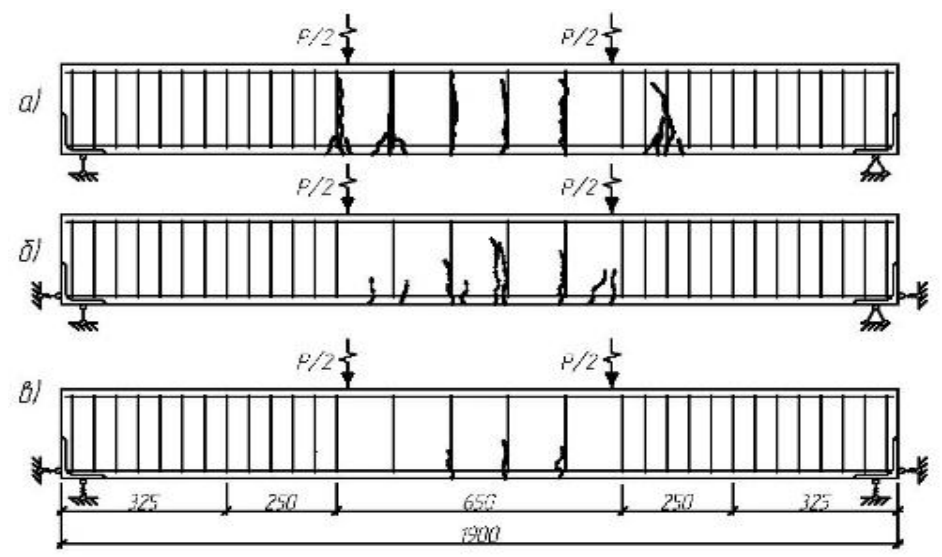

Fig. 8. The schemes of crack formation in structures under short-term dynamic loading: a) BD-4; b) BDT-5; c) BDTY-6.

Displacements analysis demonstrates that occurrence of thrust in the beam BDT-5 results in reduction of deflections in the mid-span by $41 \%$ regarding the sample BD- 4 (Fig. 7). The reduction of deflection in the structure subjected to thrust indicates higher rigidity of the thrust system. Use of yielding supports in the beams with thrust BDTY-6 reduces displacements by $68 \%$ compared to the sample BDT-5, and by $81 \%$ compared to the sample BD-4 (Fig. 7). Reduction of displacements of the structure is attributed to the yielding support straining.

Analysis of the system response alteration in time under short-term dynamic loading (Fig. 9) enables to make the following conclusion: presence of thrust in the sample BDT-5 contributes to reduction of the system response by $29 \%$ and less time is required for reaching the ultimate load with regard to the beam BD-4. In the structure BDTY- 6 the reduction of the system response was $44 \%$, and the time of reaching the maximum value of the system response also slightly decreased due to energy capacity of the yielding supports.

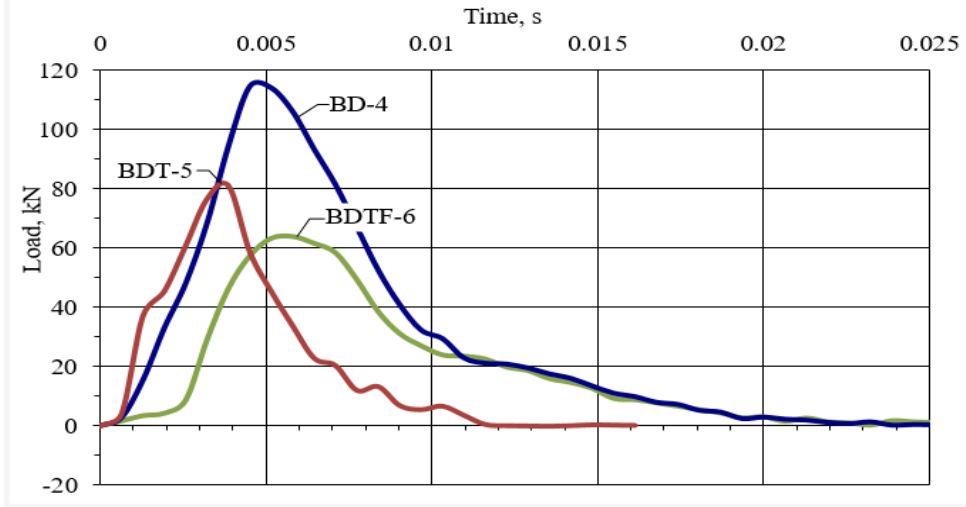

Fig. 9. Alteration in the system response in time during testing of RC beams under short-term dynamic loading.

\section{Conclusion}

The conducted experimental studies enable to establish that the presence of thrust in structures results in increase of their load-bearing capacity and reduction of deformation 
property and crack resistance both under static and intensive dynamic loading. Application of yielding supports in thrust structures provides increase in the system energy capacity (BDTY-6) and increase in the time of the beam plastic straining. A significant lag in reaction response of the structure on yielding supports takes place in this case (BDTY-6) compared to the beam on rigid supports (BD-4, BDT-5), as well as significant reduction of structural response. The results of experimental studies revealed the hided strength reserves of the beams on yielding supports with thrust. Consideration of these parameters will enable to increase the accuracy of structural analysis under short-term dynamic loading. The experimental studies are planned to be extended by changing the work of yielding supports (elastic, elasto-plastic with hardening) and the work of thrust contour by changing its rigidity.

\section{References}

1. A.A. Gvozdev, et al., Novoe o prochnosti zhelezobetona [Modern studies on reinforced concrete strength] (Strojizdat, Moscow, 1977) (in Russian)

2. L. Huynh, S. Foster, H. Valipour, R. Rendall, Construction and Building Materials 78, 153-171 (2015)

3. T.N. Vinogradova, Vlijanie raspora na rabotu zhelezobetonnyh balochnyh konstrukcij pri kratkovremennyh dinamicheskih vozdejstvijah [The effect of thrust on performance of reinforced concrete beam structures under short-term dynamic load], PhD thesis (Moscow, 1977) (in Russian)

4. D.R. Galyautdinov, Proceedings of the $62^{\text {nd }}$ Scientific University Conference of Students and Young Researchers, 21-24 (Tomsk, Russia, 26 April, 2016) (in Russian)

5. I.N. Tikhonov, Zhilishhnoe stroitel'stvo [Housing Construction] 2, 40-45 (2013) (in Russian)

6. N.N. Popov, B.S. Rastorguev, Dinamicheskij raschet zhelezobetonnyh konstrukcij [Dynamic calculation of reinforced concrete structures] (Strojizdat, Moscow, 1974) (in Russian)

7. O.G. Kumpyak, Z.R. Galyautdinov, D.N. Kokorin, Prochnost' $i$ deformativnost' zhelezobetonnyh konstrukcij na podatlivyh oporah pri kratkovremennom dinamicheskom nagruzhenii [Strength and deformability of reinforced concrete structures on yielding supports under short-term dynamic load] (TSUAB Publ., Tomsk, 2016) (in Russian)

8. A.R.A. Said, Povyshenie nesushhej sposobnosti zhelezobetonnyh konstrukcij pri vzryvnyh vozdejstvijah [Increase of bearing capacity of reinforced concrete structures under blast load], PhD thesis (Moscow, 1995) (in Russian) 